\title{
Targeting dynamic hyperinflation in moderate-to-severe asthma: a randomised controlled trial
}

\author{
Akke-Nynke van der Meer ${ }^{1}$, Kim de Jong $\mathbb{C}^{1}$, Aranka Hoekstra-Kuik ${ }^{1}$, Elisabeth $\mathrm{H}_{\text {. Bel }}{ }^{2}$ and \\ Anneke ten Brinke ${ }^{1}$
}

${ }^{1}$ Medical Centre Leeuwarden, Leeuwarden, The Netherlands. ${ }^{2}$ Amsterdam University Medical Centres, Amsterdam, The Netherlands.

Corresponding author: Akke-Nynke van der Meer (anvandermeer@yahoo.com)

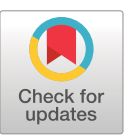

This version is distributed under the terms of the Creative Commons Attribution NonCommercial Licence 4.0. For commercial reproduction rights and permissions contact permissions@ersnet.org

This article has supplementary material available from openres.ersjournals.com

Received: 9 Oct 2020 Accepted: 23 May 2021

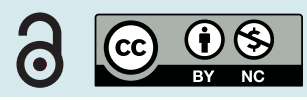

Shareable abstract (@ERSpublications)

Dynamic hyperinflation: a target for treatment in asthma, which can be reduced by systemic antiinflammatory treatment https://bit.ly/3gfyxYv

Cite this article as: van der Meer A-N, de Jong K, Hoekstra-Kuik A, et al. Targeting dynamic hyperinflation in moderate-to-severe asthma: a randomised controlled trial. ERJ Open Res 2021; 7: 00738-2020 [DOI: 10.1183/23120541.00738-2020].

\section{Abstract}

Background Dynamic hyperinflation is highly prevalent in moderate-to-severe asthma, which may significantly impede activities of daily life. We hypothesised that dynamic hyperinflation in asthma is due to inflammation of large and small airways and can be reduced by systemic anti-inflammatory treatment. Therefore, we investigated the effect of systemic glucocorticoids on dynamic hyperinflation in moderate-tosevere asthma patients and explored the relationships between inflammatory markers and changes in dynamic hyperinflation.

Methods In this randomised placebo-controlled trial we included 32 asthma patients on inhaled glucocorticoid therapy showing dynamic hyperinflation, defined by a $\geqslant 10 \%$ reduction in inspiratory capacity measured by standardised metronome-paced tachypnea test. Patients received either triamcinolone (80 mg) or placebo intramuscularly. Before and 2 weeks after treatment, patients completed respiratory health questionnaires, had blood eosinophils and exhaled nitric oxide levels measured, and underwent lung function and dynamic hyperinflation testing.

Results After adjustment for potential confounders, dynamic hyperinflation was significantly reduced by $28.1 \%$ in the triamcinolone group and increased by $9.4 \%$ in the placebo group $(p=0.027)$. In the triamcinolone-treated patients, the reduction in dynamic hyperinflation was greater in patients with higher blood eosinophils at baseline $(r=-0.592, p=0.020)$ and tended to be associated with a reduction in blood eosinophils ( $\mathrm{r}=0.412, \mathrm{p}=0.127)$ and exhaled nitric oxide $(\mathrm{r}=0.442, \mathrm{p}=0.099)$.

Conclusions This exploratory study suggests that dynamic hyperinflation in asthma can be reduced by systemic anti-inflammatory treatment, particularly in patients with elevated blood eosinophils. This supports the hypothesis that dynamic hyperinflation in asthma is due to airway inflammation and should be considered an important target for treatment.

\section{Introduction}

Asthma is a heterogeneous airway disease affecting the large and small airways exhibiting a variety in clinical, functional and inflammatory characteristics [1, 2]. Recently, we have shown that dynamic hyperinflation is highly prevalent in moderate-to-severe asthma and is associated with poorer overall health and impaired daily life activity [3]. Because of this impact on important patient-related outcomes, dynamic hyperinflation might be a new target for treatment in moderate-to-severe asthma.

$\mathrm{DH}$ is a well-known feature in COPD, but its importance in asthma has only recently been appreciated [4]. In COPD, dynamic hyperinflation is mainly due to abnormal lung mechanics caused by decreased elastic recoil, loss of alveolar attachments and collapse of small airways [5]. In asthma, however, the mechanisms underlying dynamic hyperinflation appear to be different. Studies have shown that asthma patients with systemic eosinophilic inflammation were more likely to show air trapping as compared to their non-eosinophilic controls [6], and in patients with severe asthma the degree of air trapping was shown to 
be significantly related to the level of exhaled alveolar nitric oxide [7]. These and other findings suggest that airway inflammation, particularly of the peripheral airways, may be the major contributor to reduced airway calibre, premature airway closure, air trapping and eventually dynamic hyperinflation in patients with asthma [8-10]. Conceivably, inflammation of the peripheral airways cannot be adequately controlled with inhaled glucocorticoids and therefore systemic anti-inflammatory therapy may be more suitable.

In the present study we hypothesise that in asthma patients dynamic hyperinflation is mainly caused by peripheral airway inflammation and can be reduced by systemic anti-inflammatory treatment. To that end, we investigated the effect of a single high dose of intramuscular triamcinolone on the degree of dynamic hyperinflation as measured by metronome-paced tachypnea (MPT) test in moderate-to-severe asthma patients on GINA step 4-5 treatment [11]. In addition, we explored the relationship between inflammatory markers (blood eosinophils and exhaled nitric oxide) and the change in dynamic hyperinflation.

Methods

Study participants

Patients (age $\geqslant 18$ years) with moderate-to-severe asthma, using GINA step 4-5 treatment (inhaled corticosteroids/long-acting $\beta$ agonists and/or muscarinic antagonists) [11] for at least 6 months, were consecutively recruited from an outpatient clinic of a large teaching hospital in the Netherlands (Medical Centre Leeuwarden) between June 2016 and January 2018. All patients were nonsmokers or ex-smokers with $\leqslant 10$ pack-years, had a body mass index $(\mathrm{BMI}) \leqslant 30$, had airway obstruction with a forced expiratory volume in $1 \mathrm{~s}\left(\mathrm{FEV}_{1}\right) /$ forced vital capacity $(\mathrm{FVC}) \leqslant 80 \%$ of predicted, and had stable respiratory disease prior to inclusion. A patient was considered to be atopic when showing allergen-specific IgE level of $\geqslant 0.35 \mathrm{IU} \cdot \mathrm{mL}^{-1}$ to any of the tested common respiratory allergens. Patients with concurrent respiratory disease, major comorbidities and pregnancy were excluded. The study was approved by the local medical ethics committee and all patients gave their written informed consent. The trial is registered at the Netherlands Trail Register under number NTR5873.

\section{Study design}

This study is part of a research programme on the role of dynamic hyperinflation in asthma. For the current randomised, double-blind placebo-controlled intervention study, patients were included only if the degree of dynamic hyperinflation measured by MPT was $>10 \%$ and confirmed by a cardiopulmonary exercise test [3, 12-15]. At baseline patient characteristics were collected (table 1). Patients were then randomised 1:1 to one of the two treatment arms using a randomisation list with a block size of 6 , with stratification for level of baseline blood eosinophils (threshold at $0.4 \times 10^{9}$ cells $\cdot \mathrm{L}^{-1}$ ). Two weeks after the administration of the study medication, the effect on the degree of dynamic hyperinflation was measured

\begin{tabular}{|c|c|c|c|}
\hline & Placebo & Triamcinolone & p-value \\
\hline Subjects, $\mathrm{n}$ & 16 & 15 & \\
\hline Sex male, $n(\%)$ & $9(56)$ & $9(60)$ & 1.000 \\
\hline Age years ${ }^{\#}$ & $65(55-74)$ & $63(51-67)$ & 0.452 \\
\hline Adult-onset (>18 years) asthma, $\mathrm{n}(\%)$ & $11(69)$ & $8(53)$ & 0.473 \\
\hline Atopic, n (\%) & $7(44)$ & $5(33)$ & 0.716 \\
\hline BMI $\mathrm{kg} \mathrm{m}^{-2 \text { I }}$ & $25.2 \pm 2.3$ & $26.8 \pm 2.8$ & 0.080 \\
\hline Pack-years $\#$ & $0(0-1.5)$ & $0(0-5)$ & 0.830 \\
\hline Fluticasone equivalent $\mathrm{mg}^{\#}$ & $500(500-1000)$ & $500(500-1000)$ & 0.578 \\
\hline OCS dependent, n (\%) & $3(19)$ & $2(13)$ & 1.000 \\
\hline Exacerbations, preceding year ${ }^{\#}$ & $2(0-3)$ & $2(1-5)$ & 0.493 \\
\hline Blood eosinophils $\times 10^{9} \mathrm{~L}^{-1 \#}$ & $0.2(0.1-0.4)$ & $0.2(0.1-0.3)$ & 0.951 \\
\hline$F_{\text {ENO }} \mathrm{ppb}^{\#}$ & $35(22-92)$ & $21(13-26)$ & 0.036 \\
\hline $\mathrm{Pb} \mathrm{FEV}_{1}, \%$ pred $^{\natural}$ & $66 \pm 16$ & $77 \pm 17$ & 0.235 \\
\hline $\mathrm{Pb} \mathrm{FEV}_{1} / \mathrm{FVC}$ \% pred & $65 \pm 12$ & $72 \pm 8$ & 0.060 \\
\hline FRC/TLC, \% pred & $119 \pm 14$ & $111 \pm 15$ & 0.097 \\
\hline ACQ total score ${ }^{\#}$ & $1.5(1.0-2.4)$ & $1.3(0.8-2.8)$ & 0.874 \\
\hline
\end{tabular}


by MPT test [16]. Before and 2 weeks after the administration of study medication patients completed a set of respiratory health questionnaires, had blood drawn and underwent lung function tests.

The administered study medication consisted of one single intramuscular injection of either $2 \mathrm{~mL}$ (40 mg $\cdot \mathrm{mL}^{-1}$ ) triamcinolone acetonide (Kenacort-A® “40”, Bristol-Myers Squibb, Utrecht, The Netherlands) or matched placebo ( $2 \mathrm{~mL}$ NaCL $0.9 \%$ ). Study medication was prepared and blinded at the hospital pharmacy by an independent member of the pharmacy and administered to the patients by an independent nurse. Therefore participants, care providers and those assessing outcomes remained blinded till the study ended. During the study patients continued their own medication.

\section{Study measurements}

MPT-induced dynamic hyperinflation

The degree of dynamic hyperinflation was assessed after bronchodilation with $400 \mu \mathrm{g}$ inhaled salbutamol $[12,14]$. For detailed explanation of the MPT testing procedure, see the online supplementary material. The degree of dynamic hyperinflation was calculated as the difference between the post-MPT inspiratory capacity and baseline inspiratory capacity at rest.

\section{Lung function and questionnaires}

Spirometry and body plethysmography testing were performed after inhalation of $400 \mu \mathrm{g}$ salbutamol $[17,18]$. This was followed by an exhaled nitric oxide fraction $\left(F_{\mathrm{ENO}}\right)$ measurement wherein subjects performed a slow expiratory vital capacity manoeuvre with a constant expiratory flow of $50 \mathrm{~mL} \cdot \mathrm{s}^{-1}$. Levels of $F_{\text {ENO }}$ were expressed as parts per billion (ppb) [19]. Symptoms were assessed using specific and general respiratory health questionnaires (table 2 ) [3].

\section{Statistical analysis}

Sample size

A sample size of 16 subjects per group was calculated to have $80 \%$ power (with $\alpha=0.05$ ) to detect a difference in change in dynamic hyperinflation of 50\% from pre- to post-intervention between the two groups [20].

TABLE 2 Differences between triamcinolone and placebo treatment

\begin{tabular}{|c|c|c|c|c|c|c|c|}
\hline & \multicolumn{3}{|c|}{ Triamcinolone $(n=15)$} & \multicolumn{3}{|c|}{ Placebo $(n=16)$} & \multirow[b]{2}{*}{$\begin{array}{c}\text { Between-group } \\
\text { p-value }\end{array}$} \\
\hline & Baseline & Post-treatment & $\begin{array}{c}\text { Within-group } \\
\text { p-value * }\end{array}$ & Baseline & Post-treatment & $\begin{array}{l}\text { Within-group } \\
\text { p-value * }\end{array}$ & \\
\hline $\begin{array}{l}\text { Blood eosinophils } \\
\quad \times 10^{9} \mathrm{~L}^{-1 \#}\end{array}$ & $0.2(0.1-0.3)$ & $0.1(0.1-0.2)$ & 0.010 & $0.2(0.1-0.4)$ & $0.2(0.1-0.5)$ & 0.392 & 0.011 \\
\hline $\begin{array}{l}\text { Blood neutrophils } \\
\times 10^{9} \mathrm{~L}^{-1 \#}\end{array}$ & $4.9(3.4-6.1)$ & $6.6(5.7-8.6)$ & 0.001 & $4.8(4.1-6.1)$ & $5.1(4.5-6.3)$ & 0.133 & 0.006 \\
\hline$F_{\text {ENO }} \mathrm{ppb}^{\#}$ & $21(13-26)$ & $15(12-22)$ & 0.090 & $35(22-92)$ & $34(20-70)$ & 0.088 & 0.470 \\
\hline $\mathrm{Pb} \mathrm{FEV}_{1}, \%$ pred" & $77 \pm 17$ & $87 \pm 20$ & 0.001 & $66 \pm 16$ & $69 \pm 19$ & 0.333 & 0.004 \\
\hline Pb FVC, \% pred" & $109 \pm 19$ & $116 \pm 17$ & $<0.001$ & $106 \pm 19$ & $103 \pm 17$ & 0.215 & $<0.001$ \\
\hline $\mathrm{Pb} \mathrm{FEV}_{1} / \mathrm{FVC}, \%$ pred $^{q}$ & $72 \pm 8$ & $77 \pm 11$ & 0.010 & $65 \pm 12$ & $69 \pm 14$ & 0.017 & 0.654 \\
\hline TLC, \% pred" & $114 \pm 17$ & $115 \pm 17$ & 0.100 & $110 \pm 13$ & $112 \pm 16$ & 0.199 & 0.379 \\
\hline RV, \% pred" & $141 \pm 41$ & $132 \pm 37$ & 0.268 & $148 \pm 32$ & $152 \pm 41$ & 0.552 & 0.078 \\
\hline $\mathrm{RV} / \mathrm{TLC}, \%$ pred $^{4}$ & $113 \pm 23$ & $105 \pm 22$ & 0.233 & $124 \pm 20$ & $125 \pm 22$ & 0.796 & 0.175 \\
\hline FRC, \% pred" & $138 \pm 30$ & $138 \pm 28$ & 0.932 & $142 \pm 23$ & $147 \pm 32$ & 0.242 & 0.423 \\
\hline FRC/TLC, \% pred" & $111 \pm 15$ & $114 \pm 14$ & 0.730 & $119 \pm 14$ & $120 \pm 16$ & 0.609 & 0.800 \\
\hline$A C Q$, total score ${ }^{\#}$ & $1.3(0.8-2.8)$ & $1.2(0.5-1.8)$ & 0.172 & $1.5(1.0-2.4)$ & $1.2(0.5-2.2)$ & 0.033 & 0.654 \\
\hline CCQ, total score & $1.5(0.8-2.0)$ & $0.8(0.6-1.6)$ & 0.018 & $2.0(0.7-2.3)$ & $1.6(0.6-2.5)$ & 0.876 & 0.030 \\
\hline SGRQ, total score ${ }^{\#}$ & $28.9(10.8-47.4)$ & $19.9(8.1-51.2)$ & 0.078 & $38.3(20.1-53.5)$ & $31.8(18.9-53.5)$ & 0.918 & 0.281 \\
\hline LCADL, total score & $16(15-30)$ & $16(14-24)$ & 0.207 & $22(15-35)$ & $17(15-28)$ & 0.074 & 0.654 \\
\hline SOBDA, total score & $1.2(1.0-3.1)$ & $1.3(1.0-1.8)$ & 0.657 & $1.3(1.1-2.1)$ & $1.3(1.0-1.6)$ & 0.311 & 0.626 \\
\hline
\end{tabular}

$F_{\mathrm{ENO}}$ : exhaled nitric oxide fraction; $\mathrm{Pb}$ : post-bronchodilator; $\mathrm{FEV}_{1}$ : forced expiratory volume in $1 \mathrm{~s}$; FVC: forced vital capacity; TLC: total lung capacity; RV: residual volume; FRC: functional residual capacity; ACQ: Asthma Control Questionnaire, total score; CCQ: Clinical COPD Questionnaire, total score; SGRQ: St. George's Respiratory Questionnaire, total score; LCADL: London Chest Activity of Daily Living questionnaire, total score; SOBDA: Shortness of Breath with Daily Activities questionnaire, total score; IQR: interquartile range. *: within-group p-value: difference between baseline and post-treatment values of symptoms, lung function and inflammatory parameters measured separately for the triamcinolone group and placebo group; ${ }^{* *}$ : between-group p-value: difference between the triamcinolone and placebo-induced changes in symptoms, lung function and inflammatory parameters. ": median (IQR); ": mean \pm sD. 
Analysis

First, between-group differences at baseline were investigated by independent t-tests, Mann-Whitney U-tests or Fisher's Exact test.

Primary outcome: The primary outcome was the change in postbronchodilator MPT-induced dynamic hyperinflation from baseline to post-treatment measured as the difference between dynamic hyperinflation 2 weeks after study medication minus dynamic hyperinflation at baseline as percentage of dynamic hyperinflation at baseline. The difference in change in dynamic hyperinflation between the placebo and triamcinolone group was assessed by independent t-test, followed by linear regression analyses to adjust for potential confounders, i.e. variables with baseline differences $(\mathrm{p}<0.1)$ between the two groups $\left(F_{\mathrm{ENO}}\right.$, $\mathrm{BMI}, \mathrm{FEV}_{1} / \mathrm{FVC}$ and functional residual capacity (FRC)/total lung capacity (TLC)).

Secondary outcomes: As secondary outcome, we evaluated the treatment-induced effects on symptoms, lung function and inflammatory parameters for which we used paired t-tests or Wilcoxon rank tests (within-group differences) and independent t-tests or Mann-Whitney U-tests (between-group differences). Finally, the relationship between (change in) dynamic hyperinflation and (change in) inflammatory markers was assessed by Spearman rank correlation coefficients. All analyses were performed using SPSS software, version 24 (SPSS Inc., Armonk, NY, USA).

Results

\section{Randomisation}

Seventy-seven patients were assessed for eligibility of whom 32 patients met the inclusion criteria and were enrolled in this study (see flowchart figure 1). 17 patients were randomised to placebo and 15 to triamcinolone treatment. Owing to a technically incorrect measurement, one patient randomised to placebo was excluded prior to the analyses.

\section{Baseline characteristics}

There were no significant differences between the two groups in sex, age or smoking history, but BMI tended to be slightly higher in the triamcinolone-treated patients compared to placebo (table 1). We found no difference in blood eosinophil levels, as expected after stratification; however, baseline $F_{\text {ENO }}$ was significantly lower in the triamcinolone group as compared to the placebo group (median (IQR)=21 (1326) ppb versus 35 (22-92) ppb, $\mathrm{p}=0.036$ ). There were no significant between-group differences in baseline lung function parameters, though we observed a trend towards higher $\mathrm{FEV}_{1} / \mathrm{FVC}$ and lower FRC/TLC values in the triamcinolone- versus placebo-treated patients.

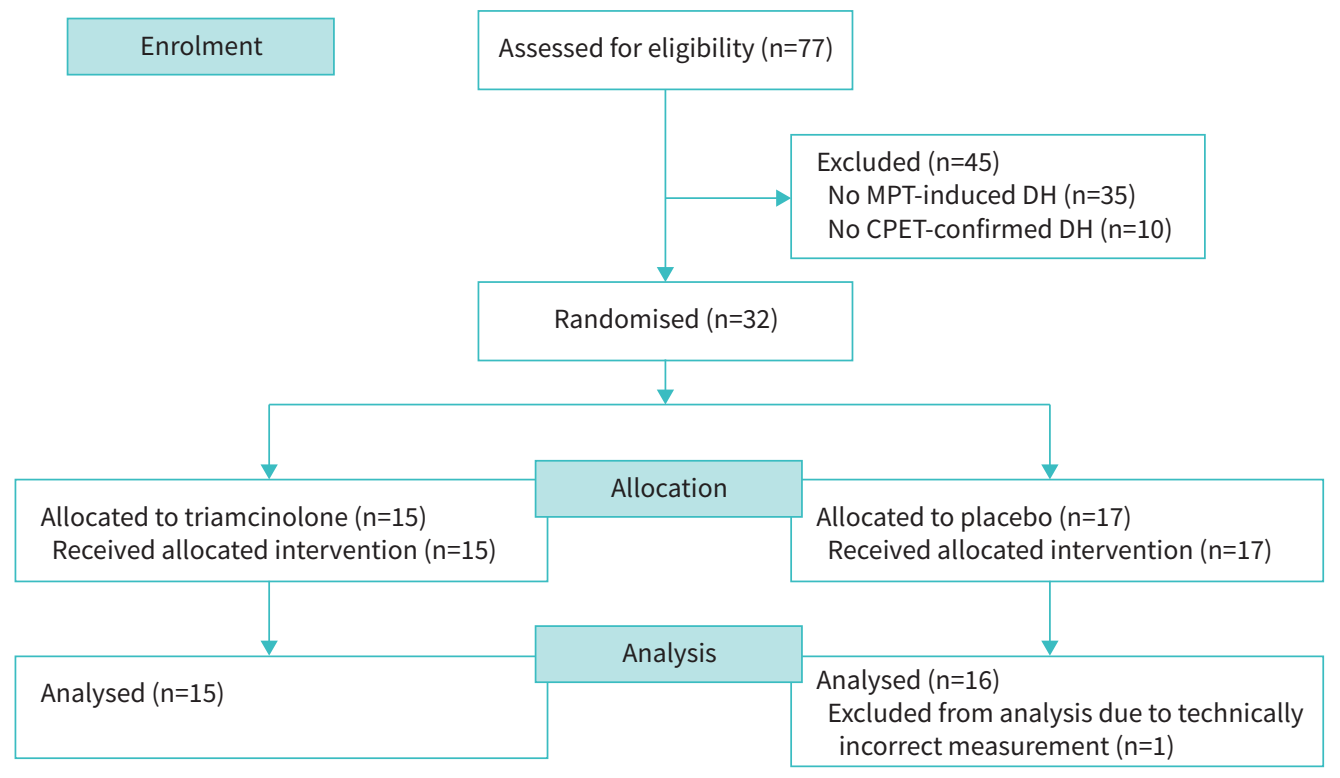

FIGURE 1 Flowchart study eligibility. DH: dynamic hyperinflation, reduction in inspiratory capacity measured as the difference between inspiratory capacity at rest and inspiratory capacity following metronome-paced tachypnea; MPT: metronome-paced tachypnea; CPET: cardiopulmonary exercise testing. 


\section{Effects of triamcinolone treatment}

\section{Effect on dynamic hyperinflation}

At baseline, there was no significant difference in the degree of postbronchodilator MPT-induced dynamic hyperinflation between the groups (median (IQR) $=600 \mathrm{~mL}(370-860 \mathrm{~mL}$ ) versus $520 \mathrm{~mL}(330-730 \mathrm{~mL}$ ) for triamcinolone versus placebo group, respectively, $\mathrm{p}=0.527$ ). Two weeks after administration of the study medication, there was a reduction in the degree of dynamic hyperinflation of $23.2 \%$ (95\% CI -46.6 to 0.25 ) compared to baseline in the triamcinolone group versus an increase of $4.8 \%$ (95\% CI -17.9 to 27.5 ) in the placebo group (between-group difference $\mathrm{p}=0.087$ ) (figure 2). After adjustment for differences in baseline $F_{\mathrm{ENO}}$, one of the potential confounding factors, it appeared that the effect of triamcinolone treatment on dynamic hyperinflation was even stronger, with a reduction of $28.1 \%$ (95\% CI -51.1 to -5.1 ) in dynamic hyperinflation in the group treated with triamcinolone and an increase of $9.4 \%$ (95\% CI -12.9 to 31.6) in the placebo group (between-group difference $\mathrm{p}=0.027$ ) (figure 3). Adjustment for other potential confounders at baseline (BMI, $\mathrm{FEV}_{1} / \mathrm{FVC}$ and FRC/TLC) did not change this result (see figure 1 in the online supplementary material).

\section{Effect on inflammatory parameters, lung function and questionnaire scores}

Blood eosinophil levels decreased and neutrophil levels increased after triamcinolone treatment, whereas these levels were unaffected by placebo (between-group differences for blood eosinophils $\mathrm{p}=0.011$ and neutrophils $\mathrm{p}=0.006$ ) (table 2).

With respect to lung function, treatment with triamcinolone significantly improved $\mathrm{FEV}_{1}$ and FVC (between-group differences $\mathrm{p} \leqslant 0.004$ ), but parameters of static hyperinflation and air trapping did not change in both treatment arms (between-group differences for FRC/TLC and residual volume (RV)/TLC $\mathrm{p} \geqslant 0.175)$.

All questionnaires showed an improvement in total scores after triamcinolone as well as placebo treatment (table 2). There was a significantly larger improvement in the Clinical COPD Questionnaire score in the triamcinolone group as compared to placebo $(\mathrm{p}=0.030)$.

\section{Dynamic hyperinflation and inflammation}

At baseline, in the group as a whole, a higher degree of dynamic hyperinflation was related to higher baseline levels of blood eosinophils $(\mathrm{r}=0.446, \mathrm{p}=0.012)$ and to higher $F_{\mathrm{ENO}}(\mathrm{r}=0.278, \mathrm{p}=0.131)$.

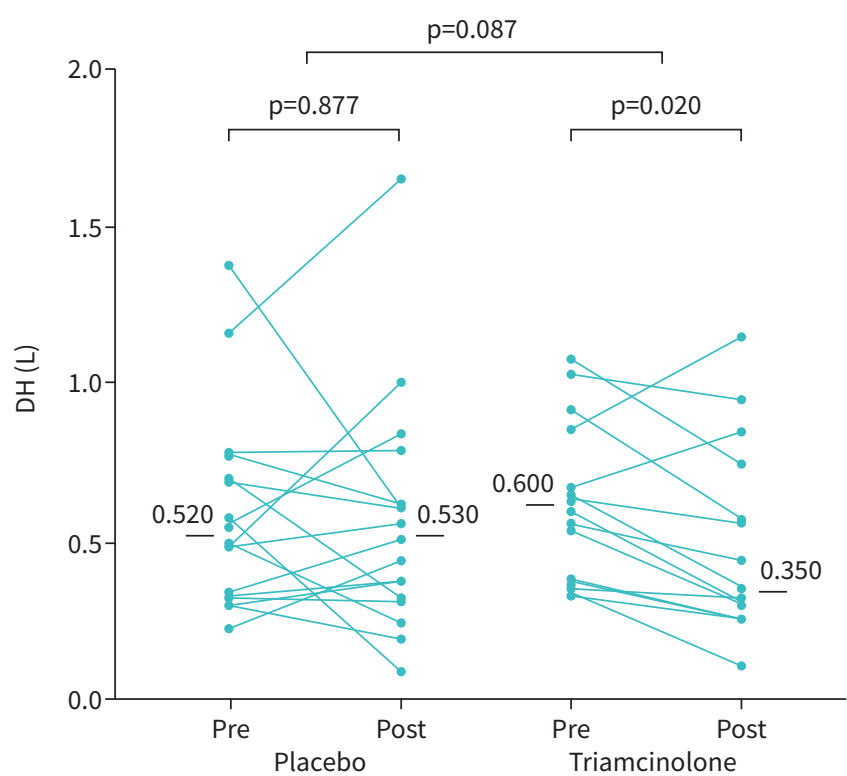

FIGURE 2 Effect of treatment with intramuscular placebo or triamcinolone on dynamic hyperinflation. DH: dynamic hyperinflation, reduction in inspiratory capacity measured as the difference between inspiratory capacity at rest and inspiratory capacity following metronome-paced tachypnoea. Data are presented as median (interquartile ranges). 


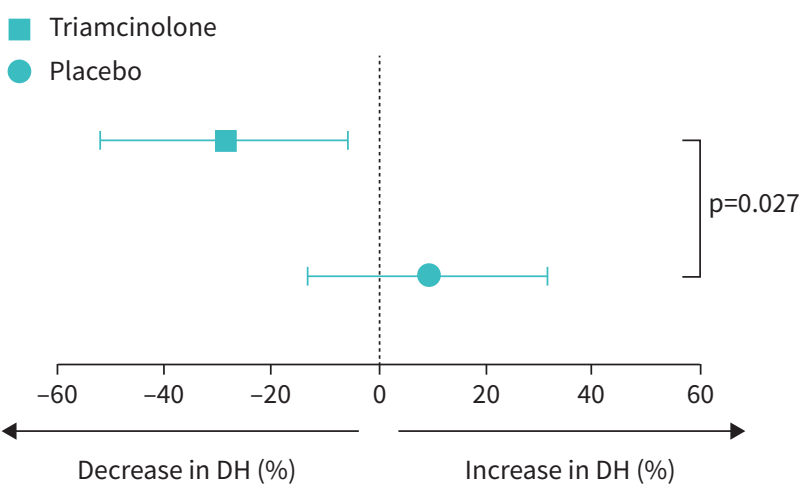

FIGURE 3 Change from baseline in dynamic hyperinflation (DH) after triamcinolone or placebo. The change measured as the difference between dynamic hyperinflation post-treatment minus dynamic hyperinflation at baseline as a percentage of dynamic hyperinflation at baseline and adjusted for differences in baseline exhaled nitric oxide fraction $\left(F_{\mathrm{ENO}}\right)$. Data are presented as the adjusted mean and $95 \%$ confidence interval estimated from the regression model conditional on the mean value for the level of $F_{\mathrm{ENO}}$ at baseline.

In addition, higher levels of blood eosinophils at baseline were associated with greater reductions in dynamic hyperinflation following treatment with triamcinolone $(r=-0.592, p=0.020)$. In the triamcinolone-treated patients, the reduction in dynamic hyperinflation tended to be related to the reduction in blood eosinophils $(r=0.412, p=0.127)$ and reduction in $F_{\text {ENO }}(r=0.442, p=0.099)$. Furthermore, in these patients the improvement in $\mathrm{FEV}_{1}$ was shown to be associated with the reduction in dynamic hyperinflation $(r=-0.603, \mathrm{p}=0.017)$.

\section{Discussion}

This study shows that the degree of dynamic hyperinflation in patients with moderate-to-severe asthma was significantly reduced by systemic anti-inflammatory treatment such as intramuscular glucocorticoids. This was independent of the degree of airway obstruction. Moreover, the decrease in dynamic hyperinflation was greater in patients with higher baseline blood eosinophils and tended to be related to a decrease in

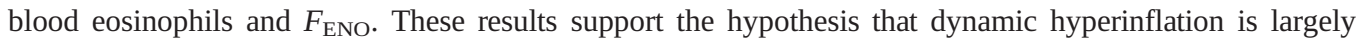
caused by airway inflammation and is therefore an important treatable trait, especially in patients with eosinophilic asthma.

Our study expands previous findings on the importance of dynamic hyperinflation in asthma and provides evidence that this disabling symptom is most prevalent in patients with elevated blood eosinophils and, unlike in patients with COPD, can be ameliorated by systemic anti-inflammatory treatment. We selected patients with dynamic hyperinflation and observed a higher age in this group as compared to regular asthma populations. In addition, the majority of our included patients with dynamic hyperinflation were male patients with an adult-onset non-atopic asthma and elevated blood eosinophils, suggesting that dynamic hyperinflation might be more prominent in the so-called "late onset eosinophilic asthma" phenotype. A few previous studies have investigated therapeutic interventions on dynamic hyperinflation in asthma. One unblinded study in 10 patients with moderate-to-severe allergic asthma showed that the degree of dynamic hyperinflation decreased with omalizumab treatment [21], whereas another study showed improvements in hyperinflation indices in a subgroup of severe asthma patients treated with benralizumab [22]. More recently, the degree of MPT-induced dynamic hyperinflation was found to be related to serum periostin levels in mild to severe asthma patients [23], again suggesting a role for inflammation in the development of dynamic hyperinflation in asthma. While the mechanisms underlying the development of dynamic hyperinflation in asthma merit further research, these and our results suggest that systemic anti-inflammatory treatments, including monoclonal antibodies, may have the potential to reduce impairments in daily life activities and improve exercise capacity by decreasing dynamic hyperinflation, at least in a subset of asthma patients.

The strengths of our study are the prospective randomised controlled design of the study, the selection of patients with exercise-test-confirmed dynamic hyperinflation, the inclusion of inflammatory parameters and the use of a solid systemic anti-inflammatory intervention. In this way, it was possible to demonstrate a clear relationship between dynamic hyperinflation and airway inflammation, as well as to provide a potential treatment option. 
Our study has limitations as well. First, there appeared to be a suboptimal balance between the groups in asthma severity (lower $F_{\mathrm{ENO}}$ and better lung function in the triamcinolone-treated group). This might create a risk of underestimation of the effects of triamcinolone, and therefore we adjusted for these variables. Second, the current study was not primarily designed to investigate the effect on symptoms or quality of life. Two weeks after trial medication we found a small improvement in favour of triamcinolone treatment for one symptom score (Clinical COPD Questionnaire), whereas the other symptom questionnaires improved equally in both treatment arms. A longer follow-up period will be necessary to evaluate whether reduction of dynamic hyperinflation indeed leads to an improvement in asthma symptoms and quality of life in the long term.

The mitigating effect of triamcinolone on dynamic hyperinflation supports a causal role for airway inflammation in the development of this phenomenon in asthma. Since the patients in our study were already treated with inhaled anti-inflammatory drugs, our findings suggest residual inflammation in the bronchial tree, which may occur in the central airways but certainly also in the peripheral airways, especially because the peripheral airways are known to be suboptimally reached by inhaled medications [24, 25]. Residual inflammation in the peripheral airways causing dynamic hyperinflation may also explain why many patients with severe eosinophilic asthma require systemic glucocorticoids or steroid-sparing biologics in addition to inhaled medication to control their disease. This is supported by studies showing that the anti-IL-5 monoclonal antibody mepolizumab improves indices of peripheral airway function [26] and computational modelling studies that confirm the impact of anti-inflammatory type 2 biologics on small airway calibre [27].

Our findings have clinical implications. The current study provides evidence that dynamic hyperinflation in asthma, a major contributing factor to asthma symptoms and impairment of daily life activities, can be treated with systemic anti-inflammatory treatments in addition to inhaled glucocorticoids and $\beta$ - 2 agonists. This differs from COPD, where dynamic hyperinflation is usually difficult to treat because it mostly results from irreversible narrowing and collapsibility of the small airways. Now that we know that in patients with Type 2 asthma dynamic hyperinflation can be reversed with systemic anti-inflammatory treatments, the long-term benefits on asthma control and quality of life have to be confirmed to further support that dynamic hyperinflation deserves a prominent place on the list of "treatable traits" [28].

In conclusion, this study shows that dynamic hyperinflation, a common and underestimated disability in patients with asthma, improves after treatment with systemic glucocorticoids. This suggests that in asthma, unlike in COPD, dynamic hyperinflation is at least partly caused by steroid-sensitive inflammatory processes in the airways. The improvement in dynamic hyperinflation was found to be most pronounced in patients with elevated blood eosinophils, suggesting that these patients will benefit most from systemic anti-inflammatory therapies like the novel anti-eosinophil biologics.

Author contributors: A-N. van der Meer contributed to development of the study design, subject recruitment, collecting study data, and performed statistical analysis and wrote the manuscript. K. de Jong contributed to statistical analysis and interpretation, and manuscript preparation. A. Hoekstra-Kuik performed the pulmonary function tests and MPT measurement. E.H. Bel and A. ten Brinke contributed to the development of the study design, statistical analysis and manuscript preparation.

This study is registered at www.trialregister.nl with identifier number NTR5873. Individual participant data will not be made available.

Conflict of interest: A-N. van der Meer reports grants from Medical Centre Leeuwarden Research Fund, unrestricted grants from TEVA and GSK, and grants from Stichting Longgeneeskunde Fryslan, during the conduct of the study. K. de Jong has nothing to disclose. A. Hoekstra-Kuik has nothing to disclose. E.H. Bel reports grants and personal fees from AstraZeneca, GSK, Novartis and Teva, personal fees from Sanofi/Regeneron, Sterna and Chiesi, outside the submitted work. A. ten Brinke reports grants from Medical Centre Leeuwarden Research Fund, unrestricted research grants from TEVA and GSK, and grants from Stichting Longgeneeskunde Fryslan, during the conduct of the study; and institutional fees for research advisory boards from GSK, Sanofi, TEVA, AstraZeneca, and Boehringer Ingelheim, and institutional fees for lectures from GSK, TEVA and AstraZeneca, all outside the submitted work.

Support statement: This study was supported by unrestricted grants from Medical Centre Leeuwarden research fund, Stichting Longgeneeskunde Fryslân, GlaxoSmithKline and Teva.

\section{References}

1 Wenzel SE, Schwartz LB, Langmack EL, et al. Evidence that severe asthma can be divided pathologically into two inflammatory subtypes with distinct physiologic and clinical characteristics. Am J Respir Crit Care Med 1999; 160: 1001-1008. 
2 Haldar P, Pavord ID, Shaw DE, et al. Cluster analysis and clinical asthma phenotypes. Am J Respir Crit Care Med 2008; 178: 218-224.

3 van der Meer AN, de Jong K, Hoekstra-Kuik A, et al. Dynamic hyperinflation impairs daily life activity in asthma. Eur Respir J 2019; 53: 1-8.

4 Garcia-Rio F, Lores V, Mediano O, et al. Daily physical activity in patients with chronic obstructive pulmonary disease is mainly associated with dynamic hyperinflation. Am J Respir Crit Care Med 2009; 180: 506-512.

5 Calverley PMA, Koulouris NG. Flow limitation and dynamic hyperinflation: key concepts in modern respiratory physiology. Eur Respir J 2005; 25: 186-199.

6 De Groot JC, Storm H, Amelink M, et al. Clinical profile of patients with adult-onset eosinophilic asthma. ERJ Open Res 2016; 2: 1-8.

7 van Veen IH, Sterk PJ, Schot R, et al. Alveolar nitric oxide versus measures of peripheral airway dysfunction in severe asthma. Eur Respir J 2006; 27: 951-956.

8 Wagner EM, Liu MC, Weinmann GG, et al. Peripheral lung resistance in normal and asthmatic subjects. Am Rev Respir Dis 1990; 141: 584-588.

9 Kraft M, Djukanovic R, Wilson S, et al. Alveolar tissue inflammation in asthma. Am J Respir Crit Care Med 1996; 154: 1505-1510.

10 Ueda $\mathrm{T}$, Niimi $\mathrm{A}$, Matsumoto $\mathrm{H}$, et al. Role of small airways in asthma: investigation using high-resolution computed tomography. J Allergy Clin Immunol 2006; 118: 1019-1025.

11 Global Initiative for Asthma (GINA). Global Strategy for Asthma Management and Prevention, 2015. https:// ginasthma.org/wp-content/uploads/2016/01/GINA_Report_2015_Aug11-1.pdf Date last accessed: 22 June 2021.

12 Gelb AF, Gutierrez CA, Weisman IM, et al. Simplified detection of dynamic hyperinflation. Chest 2004; 126: 1855-1860.

13 Lahaije AJMC, Willems LM, van Hees HWH, et al. Diagnostic accuracy of metronome-paced tachypnea to detect dynamic hyperinflation. Clin Physiol Funct Imaging 2013; 33: 62-69.

14 O'Donnell DE, Revill SM, Webb KA. Dynamic hyperinflation and exercise intolerance in chronic obstructive pulmonary disease. Am J Respir Crit Care Med 2001; 164: 770-777.

15 Lahaije AJMC, van Helvoort HAC, Dekhuijzen PNR, et al. Resting and ADL-induced dynamic hyperinflation explain physical inactivity in COPD better than FEV1. Respir Med 2013; 107: 834-840.

16 Brinke Ten A, Zwinderman AH, Sterk PJ, et al. "Refractory" eosinophilic airway inflammation in severe asthma: effect of parenteral corticosteroids. Am J Respir Crit Care Med 2004; 170: 601-605.

17 Miller MR, Hankinson J, Brusasco V, et al. Standardisation of spirometry. Eur Respir J 2005; 26: 319-338.

18 Criée CP, Sorichter S, Smith HJ, et al. Body plethysmography - its principles and clinical use. Respir Med 2011; 105: 959-971.

19 American Thoracic Society, European Respiratory Society. ATS/ERS recommendations for standardized procedures for the online and offline measurement of exhaled lower respiratory nitric oxide and nasal nitric oxide, 2005. Am J Respir Crit Care Med 2005; 171: 912-930.

20 Jones SR, Carley S, Harrison M. An introduction to power and sample size estimation: the importance of power and sample size estimation for study design and analysis. Emerg Med J 2003; 20: 453-458.

21 Schäper C, Noga O, Koch B, et al. Anti-inflammatory properties of montelukast, a leukotriene receptor antagonist in patients with asthma and nasal polyposis. $J$ Investig Allergol Clin Immunol 2011; 21: 51-58.

22 Panettieri RA, Welte T, Shenoy K V, et al. Onset of effect, changes in airflow obstruction and lung volume, and health-related quality of life improvements with benralizumab for patients with severe eosinophilic asthma: phase iiib randomized, controlled trial (SOLANA). J Asthma Allergy 2020; 13: 115-126.

23 Asano T, Ohbayashi H, Ariga M, et al. Serum periostin reflects dynamic hyperinflation in patients with asthma. ERJ Open Res 2020; 6: 00347-02019.

24 Tunon-de-Lara JM, Laurent F, Giraud V, et al. Air trapping in mild and moderate asthma: effect of inhaled corticosteroids. J Allergy Clin Immunol 2007; 119: 583-590.

25 Berry M, Hargadon B, Morgan A, et al. Alveolar nitric oxide in adults with asthma: evidence of distal lung inflammation in refractory asthma. Eur Respir J 2005; 25: 986-991.

26 Farah CS, Badal T, Reed N, et al. Mepolizumab improves small airway function in severe eosinophilic asthma. Respir Med 2019; 148: 49-53.

27 Foy BH, Soares M, Bordas R, et al. Lung computational models and the role of the small airways in asthma. Am J Respir Crit Care Med 2019; 200: 982-991.

28 Agusti A, Bel E, Thomas M, et al. Treatable traits: toward precision medicine of chronic airway diseases. Eur Respir J 2016; 47: 410-419. 